\title{
A Case Report: An Overweight Patient with High Dose Insulin Usage
}

\author{
Burcin Meryem Atak*, Mustafa Ramiz Tel \\ Department of Internal Medicine, Abant Izzet Baysal (AIB) University Hospital, Bolu, Turkey.
}

\begin{abstract}
Insulin is vital for patients with type 1 diabetes and useful for certain patients with type 2 diabetes [1]. In this article we aim to explain a case wrongly using high dosage insulin. A 68-year-old female patient with known 10 years of type 2 diabetes mellitus and hypertension came to our outpatient clinic because her blood glucose levels were high at home. She was using perindopril $10 \mathrm{mg}$, metformin and insulin. Since the patient did not want to make multiple injections her previous doctor has changed her therapy from glargine $\mathrm{u} 3001 \mathrm{x} 50$ units and insulin aspart 3x30 units to a mixed insulin; insulin degludec + insulin aspart, as 2x 40 units per day. However, the patient did not understand the change of treatment and made the combination of insulin glargine u300 1x50 units and insulin degludec + insulin aspart two times a day as 30 units. She was using this therapy more than two months.
\end{abstract}

Diabetes and complications of diabetes is a challenging healthcare problem. Especially patients' education is as important as the drug therapy $[2,3]$. Among serious side-effects of insulin therapy are overdose, resulting in severe hypoglycemia, causing seizures, coma and even death [1]. Patients must be well educated about the risks of using high doses of insulin.

Keywords: High dose insulin, Obesity, Type 2 diabetes mellitus, Patient education, Hypoglycemia, Insulin overdose.

\section{INTRODUCTION}

Insulin is vital for patients with type 1 diabetes and useful for certain patients with type 2 diabetes [1]. Current international guidelines list insulin treatment as a possible second line therapy in patient with unsatisfactory glucose control on monotherapy with metformin [4]. But even before the treatment with metformin alone, patients' education and life style modification is the first line of treatment that should be given. Doctors must be aware of the side effects of insulin therapy. In this article we aim to explain a case wrongly using high dosage insulin.

\section{CASE}

A 68-year-old female patient with known type 2 diabetes mellitus and hypertension came to our outpatient clinic because her blood glucose levels were high. She had been measuring her blood glucose levels high at home for weeks before referring to hospital. She has been feeling well, that's why she did not seek help sooner. But lately she has been dizzy and feeling exhausted. She had no other complaints.

She had been diagnosed as type 2 diabetes for at least 10 years. She has been using perindopril $10 \mathrm{mg}$ for hypertension, metformin and insulin for diabetes for a long time. Since the patient did not want to make multiple injections, her previous doctor changed her therapy from glargine u300 1x50 units and insulin aspart $3 \times 30$ units to a mixed insulin; insulin degludec + insulin aspart, as 2x40 units per day. However, the patient did not understand the change of treatment and used

*Address correspondence to this author at the Department of Internal Medicine, Abant Izzet Baysal (AIB) University Hospital, Bolu, Turkey.

E-mail: burcinatak@hotmail.com the combination of insulin u300 1x50 units and insulin deglu$\mathrm{dec}+$ insulin aspart 2 times a day as 30 units. She was using this therapy more than two months. However the patient did not experience a single episode of hypoglycemia due to this high dose of insulin. She compensated this high dose with more carbohydrate intake. As a result she came to the clinic with complaints of hyperglycemia.

In the physical examination of the patient, her height was measured as $158 \mathrm{~cm}$, her weight as $96 \mathrm{~kg}$, waist circumference as $132 \mathrm{~cm}$, and body mass index (BMI) 38. Arterial blood pressure was $145 / 90 \mathrm{~mm} / \mathrm{HG}$ and other system examinations were normal. Her blood test results showed; blood glucose of $350 \mathrm{mg} / \mathrm{dl}$ and HbA1c $11 \mathrm{mg} / \mathrm{dl}$. The patient was hospitalized in our clinic to regulate blood sugar and patient education. The insulin glargine u300 she used was discontinued. Diet and diabetes training was given to the patient. Exercise was recommended and actively enforced to the patient during hospitalization. A suitable diabetic diet has been given to the patient by the hospitals nutritionist and an extensive diabetic diet education was given. The blood glucose regulation was achieved by increasing the mix insulin doses by 4 units. Diabetic complications were screened and necessary consultations were made. She was discharged with regulated blood glucose and good health.

\section{DISCUSSION}

Diabetes and complication of diabetes is a challenging healthcare problem. Especially patients' education is as important as the drug therapy [2, 3]. Among serious consequences of insulin-related medication errors are overdose, resulting in severe hypoglycemia, causing seizures, coma and even death [1]. Patients must be well educated about the risks of using 
high doses of insulin. Several studies have looked at the different choices of patient education tools for insulin and found that even higher educated patients, and patient who have been using insulin for a long time, may need well developed learning tools [5-7].

Despite intuition; insulin use, particularly in high doses, is associated with weight gain $[2,3,8]$. American Diabetes Association guidelines and American Association of Clinical Endocrinologists/ American College of Endocrinology (AACE/ACE) guidelines suggest minimizing the use of concomitant medications that may cause weight gain when treating patients with type 2 diabetes [9]. Not only high dose insulin but combination of drugs can cause patient to gain weight. Our patient was obese with the BMI 38. When asked she declared that she gained more weight over the last two months then the last five years. For the last two months she has been using high dose insulin and metformin. Doctors usually know and warn their patients about the insulin's hypoglycemic effects but weight gain is usually overlooked. Even some doctors are unaware of this effect. Our patient felt safe because she was using high dose insulin and kept eating unhealthy food more than usual. With the weight gain, patients may need more insulin than the prescribed dose. And with the higher insulin dose, the risk of hypoglycemic episode gets higher. It's a vicious circle that must be broken. And usually it takes hospitalization to regulate blood glucose and insulin dosage once the patient goes into this circle.

As a result, patients must be educated about diabetes and insulin therapy even before the treatment begins. There is no such thing as glycemic control with high dose insulin. Life style modification and patients behavior change is the key in treatment.

\section{AUTHORS' CONTRIBUTION}

All authors have equally contributed.

\section{CONFLICT OF INTEREST}

Declared none.

\section{ACKNOWLEDGEMENTS}

Declared none.

\section{REFERENCES}

[1] Prescrire Editorial Staff. Insulin use: Preventable errors. Prescrire Int 2014; 23(145): 14-7.

[2] Holman RR, Farmer AJ, Davies MJ, et al. Three-year efficacy of complex insulin regimens in type 2 diabetes. N Engl J Med 2009; 361(18): 1736-47. DOI: 10.1056/NEJMoa0905479

[3] Holman RR, Thorne KI, Farmer AJ, et al. Addition of biphasic, prandial, or basal insulin to oral therapy in type 2 diabetes. N Engl J Med 2007; 357(17): 1716-30. DOI: 10.1056/NEJMoa075392

[4] Haluzik M. Long-acting insulins in the treatment of type 2 diabetes and their position in the current treatment algorithm. Vnitr Lek 2017; 63(2): 87-92.

[5] Das Choudhury S, Das SK, Hazra A. Survey of knowledge-attitude-practice concerning insulin use in adult diabetic patients in eastern India. Indian J Pharmacol 2014; 46(4): 425-9. DOI: 10.4103/0253-7613.135957

[6] Kalra S. Patient barriers to insulin: The InfoCRIne order. J Pak Med Assoc 2018; 68(3): 494-6.

[7] Taylor CG, Jr., Bynoe K, Worme A, et al. A checklist that enhances the provision of education during insulin initiation simulation: A randomized controlled trial. Diabet Med 2016; 33(9): 1204-10. DOI: 10.1111/dme.12956

[8] Jansen HJ, Vervoort GM, de Haan AF, et al. Diabetes-related distress, insulin dose, and age contribute to insulin-associated weight gain in patients with type 2 diabetes: Results of a prospective study. Diabetes Care 2014; 37(10): 2710-7. DOI: $10.2337 / \mathrm{dc} 13-1205$

[9] American Diabetes Association. 8. Obesity Management for the Treatment of Type 2 Diabetes: Standards of Medical Care in Diabetes-2020. Diabetes Care 2020; 43(Suppl 1): S89-S97. DOI: $10.2337 / \mathrm{dc} 20-\mathrm{S} 008$ 